\title{
Effects of treated sewage effluent on immune function in rainbow trout (Oncorhynchus mykiss)
}

\author{
Birgit Hoeger $^{\mathrm{a}}$, Michael R. van den Heuvel ${ }^{\mathrm{b}}$, Bettina C. Hitzfeld ${ }^{\mathrm{c}}$, Daniel R. Dietrich ${ }^{\mathrm{a}, *}$ \\ a Environmental Toxicology, University of Konstanz, P.O. Box X918, D-78457 Konstanz, Germany \\ ${ }^{\mathrm{b}}$ Forest Research, Private Bag 3020, Sala St., Rotorua, New Zealand \\ ${ }^{\mathrm{c}}$ Swiss Agency for the Environment, Forests and Landscape (SAEFL), Substances, Soil, \\ Biotechnology Division, Section Substances, 3003 Bern, Switzerland
}

\begin{abstract}
In this study, the immune reactions of rainbow trout (Oncorhynchus mykiss) were examined, after exposure to 10, 30 and $70 \%$ of tertiary-treated municipal sewage effluent for 27 days. Exposures were conducted concurrently with and without an immune challenge using intraperitoneal injections of inactivated Aeromonas salmonicida salmonicida. Due to the time required to prepare and analyse samples, fish sampling was conducted over two consecutive days. There was no trout mortality for any of the experimental treatments. The exposure to effluent increased in vitro lymphocyte proliferation, decreased circulating lymphocytes and increased degrading erythrocytes in peripheral blood samples. Circulating lymphocytes were only decreased in the sham-injected, but not in the A. salmonicida-injected group. In addition to effluent effects, circulating lymphocytes and lymphocyte proliferation were decreased on day 2 of sampling as compared to day 1 . Concentration-dependent degradation of erythrocytes was only observed on day 2 of sampling. Capture and removal of trout on day 1 of sampling presumably caused low-level stress that affected some results on day 2. Oxidative burst, phagocytosis, lysozyme, leucocyte populations other than lymphocytes and A. salmonicida-specific IgM production were not affected by exposure to effluent, and of these parameters, only oxidative burst and total leucocytes showed sampling day effects. From these results it can be observed, that with the exception of oxidative burst, those variables affected by effluent exposure were also significantly changed by the low-level sampling stress imposed by staggered sampling. Elevated liver mixed-function oxygenase activity as measured by 7-ethoxyresorufin- $O$ deethylase activity, and increased bile polycyclic aromatic hydrocarbon $(\mathrm{PAH})$ metabolites were observed in response to sewage effluent exposure. As both PAHs and stress are known immune suppressors, it is difficult to conclude whether or not changes in immune parameters due to effluent exposure were caused by the direct action of chemicals, or were due to a general stress response.
\end{abstract}

Keywords: Rainbow trout; Oncorhynchus mykiss; Fish immunology; Aeromonas salmonicida salmonicida; Sewage treatment effluent

\footnotetext{
* Corresponding author. Tel.: +49 7531 883518; fax: +49 7531883170.

E-mail address: daniel.dietrich@uni-konstanz.de (D.R. Dietrich).
} 


\section{Introduction}

Sewage treatment plant effluents have been shown to contain low levels of a wide range of anthropogenic substances, including pharmaceutical residues, substances found in health care products and industrial chemicals (Daughton and Ternes, 1999; Kummerer, 2001). The potential of some of the substances found in sewage and in the receiving environment to disrupt reproductive-endocrine and immune mechanisms in wildlife has raised concerns about possible effects of such contamination on animal and human health, as well as on the integrity of fish populations (Guillette and Guillette, 1996; Jobling et al., 1998). Impairment of immune mechanisms in aquatic organisms due to pollution of our surface waters may lead to reduced resistance against opportunistic pathogens. Therefore, along with reproductive-endocrine disruption, effects of contaminants on immune competence in aquatic organisms requires further study (Luebke et al., 1997).

Despite the growing interest in the field of fish immunotoxicology, basic knowledge about effects, mechanism of action and environmental relevance of pollutants for the fish immune system is still sparse to date. Although effects of different substances on selected immune parameters in fish have been investigated, no clear pattern for immunomodulating activity has been found. The impacts of complex effluent exposure, e.g. sewage treatment plant (STP) effluent, is difficult to assess and has received relatively little scientific attention. A field study in southeast UK has shown reduced lymphocyte proliferation and lower serum lysozyme activity in carp (Cyprinus carpio) exposed to river water for 47 days compared to a reference water site (Price et al., 1997). Reduced erythrocyte, granulocyte and lymphocyte numbers in cardiac blood, as well as lower blood cell phagocytic activity have been observed in goldfish (Carassius auratus), exposed to treated sewage in a laboratory experiment (Kakuta, 1997).

The current study investigated the short-term effects of a tertiary-treated municipal STP effluent on the immune system of rainbow trout (Oncorhynchus mykiss) in a controlled laboratory situation to give a first insight into possible immunomodulating activity in this fish species. Injection of fish with an inactivated form of the fish-specific pathogen Aeromonas salmonicida salmonicida was used to activate the immune system and consequently enable the investigation of effects of effluent on reactivity against a threatening disease. The use of inactivated $A$. salmonicida enables the investigation of immune reactions against the bacterial surface molecules, while death of the exposed animals, as could be expected in a challenge with a living pathogen, is avoided. In addition to the immune parameters, liver 7-ethoxyresorufin- $O$-deethylase (EROD) activity was used as an indicator of alterations in mixed-function oxygenase activity (MFO). PAH metabolites in bile samples were determined as they are a substance class that has previously been observed to affect immune reactions in fish, including a decrease in circulating lymphocyte numbers (Karrow et al., 1999; Khan, 2003).

\section{Materials and methods}

\subsection{Experimental setup}

One-year-old rainbow trout (O. mykiss), obtained from the New Zealand Fish and Game Ngongataha hatchery (Rotorua, New Zealand), were anaesthetised with $0.1 \%$ ethyl-3-aminobenzoate methanosulfonate (MS222; Fluka, Switzerland) and either injected i.p. with $3 \times 10^{8}$ formaldehyde-inactivated A. salmonicida cells (strain MT 423) per $100 \mathrm{~g}$ body weight or with an equivalent volume of PBS as a control for the injection (sham-injection). Inactivated A. salmonicida antigen was kindly provided by Bernd Köllner and Günter Kotterba, Friedrich-Löffler-Institut, Greifswald-Insel Riems, Germany. Average \pm S.D. body weight and length of trout were $175 \pm 56 \mathrm{~g}$ and $24.8 \pm 2.3 \mathrm{~cm}$, respectively. Rainbow trout, held in $80 \mathrm{~L}$ glass aquaria, were then exposed to either de-chlorinated tap water (aquifer source) or 10, 30 or $70 \%$ (v/v) STP effluent for 27 days, using $10 \mathrm{~A}$. salmonicida-injected and 10 sham-injected fish per treatment. Final treated effluent was obtained from a municipal sewage treatment plant located in Rotorua, New Zealand (population $\sim 58,000$, capacity of $\sim 18,000 \mathrm{~m}^{3}$ sewage daily). This STP employs a pre-treatment step with stop screens and a grit trap, a primary treatment step with sedimentation and secondary activated sludge treatment (Bardenpho Reactor). Water and effluent in the exposure aquaria was exchanged daily by static renewal of $50 \%$. Conductivity, temperature, $\mathrm{pH}$ and dissolved oxygen were measured daily and conductivity was used to calculate 
percentage of effluent in the aquaria. Average \pm S.D. for temperature $\left({ }^{\circ} \mathrm{C}\right), \mathrm{pH}$ and dissolved oxygen $(\mathrm{mg} / \mathrm{ml})$ were $15.7 \pm 0.4,7.17 \pm 0.1$ and $8.7 \pm 0.4$, respectively, for tap water control, $15.5 \pm 0.4,7.24 \pm 0.1$ and $8.8 \pm 0.3$, respectively, for $10 \%$ effluent, $15.7 \pm 0.4$, $7.42 \pm 0.01$ and $8.7 \pm 0.3$, respectively, for $30 \%$ effluent and $15.9 \pm 0.7,7.69 \pm 0.01$ and $8.7 \pm 0.3$, respectively for $70 \%$ effluent. Trout were fed daily with commercial feed pellets (Reliance Stock Food, Dunedin, New Zealand) at a ration of $0.7 \%$ of wet body weight.

\subsection{Sampling}

After 27 days of exposure, fish were sampled on two consecutive, subsequent days (days 28 and 29), whereby five A. salmonicida-injected and five PBSinjected fish from every treatment group were used per day. The two subsequent sampling days were necessary due to the high number of fish and broad sampling regimen used in the study. Fish were sacrificed, weighed, and their length determined. Peripheral blood was taken from the caudal vein and used for blood smears, to prepare lymphocytes for a lymphocyte proliferation assay and for serum samples for the determination of lysozyme activity and $A$. salmonicida-specific antibodies. Bile samples were stored at $-80{ }^{\circ} \mathrm{C}$ pending PAH-metabolite analysis. Liver and spleen were dissected and weighed. Head kidney was maintained on ice in Leibovitz's L-15 medium (Invitrogen, Auckland, New Zealand), containing 10 units (U) heparin sodium salt/mL (Sigma, St. Louis, MO, USA) and $100 \mathrm{U} / \mathrm{mL}$ penicillin/streptomycin (Pen/Strep; Invitrogen, Auckland, New Zealand), until it was used to prepare macrophages for phagocytosis and oxidative burst assays. A $0.5 \mathrm{~g}$ sample of liver was snap-frozen in liquid nitrogen and kept at $-80^{\circ} \mathrm{C}$ for subsequent determination of EROD activity.

\subsection{Differential white blood cell counts}

Blood smears were stained according to the panoptic staining by Pappenheim (May-Gruenwald/Giemsa staining). Photographs of the blood smears were taken with a SV Micro Sound Vision colour camera (Sound Vision Inc., Boston, USA) on a microscope (Zeiss Axiolab) using Axio Vision Version 2.0.5 (Carl Zeiss Vision $\mathrm{GmbH}$, Hallbergmoos, Germany). Approximately 1500 cells were counted per slide using the digital im- ages. Blood cell populations were expressed as percentage of total cells counted.

\subsection{Head kidney macrophage activity}

The preparation of head kidney macrophages was performed according to Secombes (1990) using a Percoll gradient (Sigma, St. Louis, MO, USA). Cell numbers were assessed using trypan blue exclusion and the resulting cell suspension was adjusted to a density of $1 \times 10^{6}$ viable cells $/ \mathrm{mL}$ in L-15 medium, containing Pen/Strep and seeded into 96-well black fluorometer plates (BMG Labtechnologies, Offenburg, Germany) at a density of $1 \times 10^{5}$ cells per well. After incubation at $18{ }^{\circ} \mathrm{C}$ for $90 \mathrm{~min}$, attached cells were used for phagocytosis and oxidative burst assays. Medium and unattached cells were removed by inverting the plate and careful drying on a paper towel.

For the phagocytosis assay, a volume of $100 \mu \mathrm{L}$ of a $250 \mu \mathrm{g} / \mathrm{mL}$ fluorescein-labeled Escherichia coli (K12 strain, Molecular Probes, Eugene, USA) suspension was added to each well including eight blank wells that did not contain macrophages. After incubation at $18^{\circ} \mathrm{C}$ for $2 \mathrm{~h}, E$. coli were removed by inverting the plate. Subsequently, $100 \mu \mathrm{L}$ trypan blue solution $(0.025 \%)$ was added to each well. The trypan blue solution was removed after $1 \mathrm{~min}$ of incubation and fluorescence was measured in a microplate fluorometer (Polarstar Galaxy, BMG Labtechnologies, Offenburg, Germany) with $485 \mathrm{~nm}$ excitation and $520 \mathrm{~nm}$ emission filters.

The oxidative burst assay was based on the method of Rosenkranz et al. (1992). Either $200 \mathrm{ng} / \mathrm{mL}$ phorbol12-myristate-acetate (PMA) (Sigma, St. Louis, MO, USA) in HBSS or HBSS alone was pipetted onto the cells. Measurement of the oxidative burst reaction was started $5 \mathrm{~min}$ later by the addition of $2^{\prime}, 7^{\prime}$-dichlorodihydrofluorescein diacetate $\left(\mathrm{H}_{2}\right.$ DCFDA) (Molecular Probes, Eugene, USA) to a final concentration of $10 \mu \mathrm{g} / \mathrm{mL}$. The time course of $\mathrm{H}_{2} \mathrm{O}_{2}$ production was measured in a microplate fluorometer $(485 \mathrm{~nm}$ excitation and $520 \mathrm{~nm}$ emission filters) by detecting the oxidation of $\mathrm{H}_{2}$ DCFDA to dichlorofluorescein (DCF) over a time period of $15 \mathrm{~min}$. The slope was obtained using the linear portion of the reaction curve, usually between 4 and $10 \mathrm{~min}$. Results were calculated as pmol DCF produced per well and min, using a DCF standard curve (Acros, Schwerte, Germany). 


\subsection{Lymphocyte proliferation}

The preparation of lymphocytes from rainbow trout peripheral blood followed the description of Karrow et al. (1999). Leucocytes were resuspended in L15 medium (Invitrogen, Auckland, New Zealand), counted in a haemocytometer with the help of trypan blue dye exclusion, adjusted in L-15 medium (containing 10\% fetal calf serum (FCS) and $100 \mathrm{U} / \mathrm{mL}$ Pen/Strep, both from Invitrogen, Auckland, New Zealand) to a density of $0.5 \times 10^{6}$ cells $/ \mathrm{mL}$ and seeded in 24-well cell culture-plates $(1 \mathrm{~mL} /$ well) (Invitrogen, Auckland, New Zealand). After keeping the cells at $18^{\circ} \mathrm{C}$ for $3 \mathrm{~h}$ to enable attachment to the cell culture plate, the cells were stimulated with either $100 \mu \mathrm{g}$ LPS/well (LPS from E. coli serotype 0111:B4, Sigma, USA) or $20 \mu \mathrm{g}$ Concanavalin A/well (Con A; from Canavalia ensiformis Type VI, Sigma, USA). After stimulation of lymphocyte proliferation with mitogens, the cells were kept in culture at $18{ }^{\circ} \mathrm{C}$ for $72 \mathrm{~h}$. Cells were then incubated for a further $18 \mathrm{~h}$ with $3.7 \times 10^{4} \mathrm{~Bq}$ $(1 \mu \mathrm{Ci})$ thymidine-methyl- ${ }^{3} \mathrm{H}$ per well (Amersham Pharmacia Biotech, New Zealand). Cells were vacuumfiltered onto GF/C filter paper (Whatman, UK) and filters were transferred to scintillation vials with $5 \mathrm{~mL}$ of scintillation cocktail ( $2 \mathrm{~L}$ toluene, $1 \mathrm{~L}$ Triton $\mathrm{X}$ 100, $18 \mathrm{mM}$ 2,5-diphenyloxazole (PPO), $0.55 \mathrm{mM}$ 1,4-bis[2-5-phenyloxazolyl]benzene (POPOP)). Cell proliferation was measured in a Packard BioScience liquid scintillation analyser Tri-Carb $2100 \mathrm{TR}$, as counts per min (cpm) and expressed as ratio of cpm measured with mitogen-stimulated cells to control (unstimulated) cells.

\subsection{Lysozyme activity in trout plasma}

The method for measuring serum lysozyme followed the description of Ellis (1990) (turbimetric assay), using a Micrococcus lysodeikticus (Sigma, St. Louis, MO, USA) suspension with a concentration of $0.5 \mathrm{mg} / \mathrm{mL}$. Lysozyme activity was expressed as decrease of optical density (OD) per min.

\subsection{A. salmonicida-specific antibody ELISA}

Inactivated A. salmonicida antigen and the trout IgM-specific antibody 4C10 was kindly provided by Bernd Köllner and Günter Kotterba (Friedrich-Löffler-
Institut, Germany). The ELISA for the detection of A. salmonicida-specific antibodies in trout serum followed the description of Köllner and Kotterba (2002), except for sample dilution (1:100) and detection, which was carried out using TMB (Sigma, St. Louis, MO, USA). The colour reaction was stopped by the addition of $1 \mathrm{M} \mathrm{H}_{2} \mathrm{SO}_{4}$ and absorption was measured at $450 \mathrm{~nm}$ in an SLT plate reader 340 ATTC (SLT Labinstruments, Groedig, Austria). As no standards were available for IgM determination, results are given as optical density. To enable comparison without a standard curve, all samples were measured in parallel in a single ELISA run, which was repeated once.

\subsection{Liver EROD activity}

Hepatic MFO activity was estimated in postmitochondrial supernatant (PMS) as 7-ethoxyresorufin- $O$-deethylase (EROD) activity, using a modification of the fluorescence plate-reader technique outlined by van den Heuvel et al. (1999). Frozen liver pieces were homogenised in a cryopreservative buffer $(0.1 \mathrm{M}$ phosphate, $1 \mathrm{mM}$ EDTA, $1 \mathrm{mM}$ dithiothreitol, and 20\% glycerol, pH 7.4) and spun at $9000 \times g$ to obtain the PMS. The EROD reaction mixture contained $0.1 \mathrm{M}$ Hepes buffer pH 7.8 (Sigma, St. Louis, MO, USA), $5.0 \mathrm{mM} \mathrm{Mg}{ }^{2+}, 0.5 \mathrm{mM}$ NADPH (Applichem, Darmstadt, Germany), $1.5 \mu$ M 7-ethoxyresorufin (Sigma, St. Louis, MO, USA) and $0.5 \mathrm{mg} / \mathrm{mL}$ of PMS protein. EROD activity was determined kinetically in 96-well plates, taking one reading every minute for $10 \mathrm{~min}$ on a BMG Polarstar Galaxy microplate fluorometer. Resorufin was determined using $544 \mathrm{~nm}$ excitation and $590 \mathrm{~nm}$ emission filters. Protein content was estimated from fluorescamine (Sigma, St. Louis, MO, USA) fluorescence (390 nm excitation, $460 \mathrm{~nm}$ emission filters) against bovine serum albumin (Sigma, St. Louis, MO, USA). EROD activity was calculated as pmol resorufin produced per min and $\mathrm{mg}$ protein.

\subsection{Fixed wavelength fluorescence analysis of PAHs in bile}

PAH levels in bile were analysed with fixed wavelength fluorescene analysis as described by Aas et al. (2000). Bile was diluted 1600 -fold in 50\% ethanol. A Waters 474 fluorescence detector was used for measurements with excitation and emission 


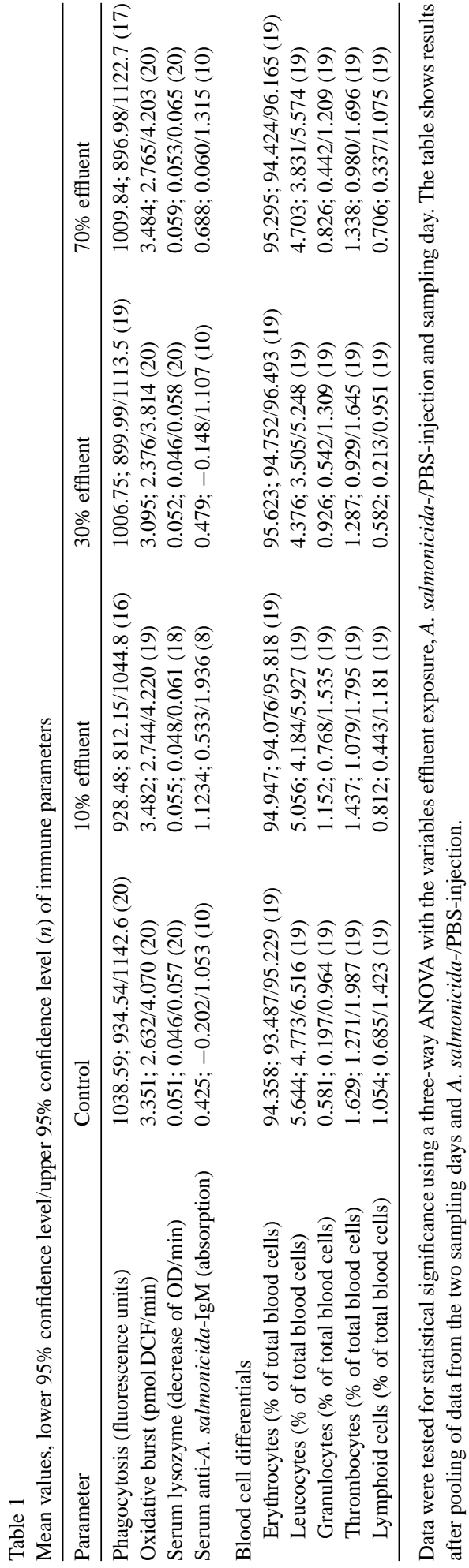

wavelengths of 290/335 for naphthalene, 341/383 for pyrene, and 380/430 for benzo[a]pyrene and slit width of $18 \mathrm{~nm}$.

\subsection{Statistics}

All immune endpoints were examined using a threeway ANOVA that included the independent variables sampling day, A. salmonicida-injection and effluent treatment and the possible interactions. Non-significant terms were progressively eliminated from the ANOVA model. Dunnett's post-hoc test was used to examine differences between the reference and exposure groups. All data were examined for normality and heteroscedasticity and were $\log$ transformed only where those assumption were not met. Transformed data were re-tested and met the assumptions required for parametric statistics in all cases, with the exception of EROD and bile data. EROD and bile data did not conform to the assumptions of parametric analysis and were instead compared using a non-parametric Kruskal-Wallis one-way analysis of variance with Bonferroni adjustment for multiple comparisons. Statistical testing was performed using the SYSTAT ${ }^{\circledR}$ software package (Wilkinson, 1990). The critical level of significance for all analyses was $\alpha=0.05$.

\section{Results}

In the present study, no mortalities occurred and fish did not show any gross external or internal disease symptoms. Neither macrophage activity (phagocytosis and oxidative burst) nor serum lysozyme activity were observed to be affected by exposure of rainbow trout to STP effluent (Table 1). Injection of trout with the inactivated bacteria A. salmonicida did not appear to significantly influence any of those immune parameters compared to sham-injected fish. The oxidative burst assay showed a statistically significant effect of sampling day, but the macrophage function phagocytosis and serum lysozyme did not demonstrate this effect. ELISA analysis of serum samples for IgM antibodies against $A$. salmonicida revealed no measurable $A$. salmonicidaantibody production in sham-injected trout, so statistical analysis was performed only on A. salmonicidainjected fish. Neither the exposure to sewage effluent, nor the day of sampling had any significant effect on serum anti-A. salmonicida IgM production (Table 1). 


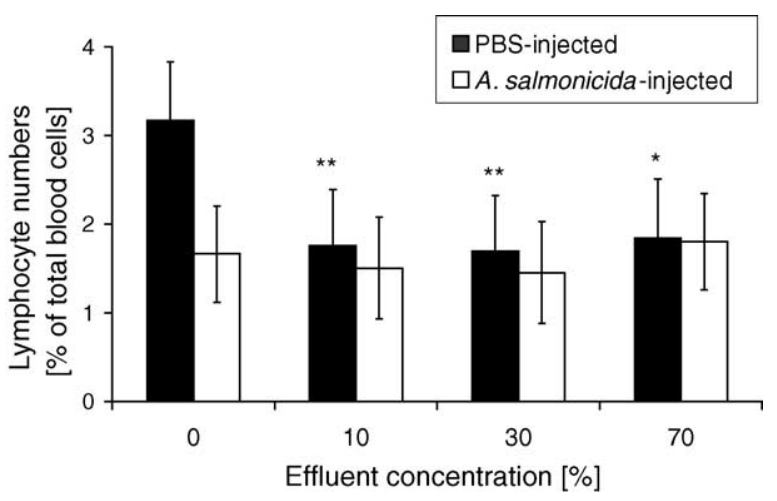

Fig. 1. Peripheral blood lymphocyte numbers as percent of total blood cells counted. Data were tested using a three-way ANOVA with the variables effluent exposure, A. salmonicida-/PBS-injection and sampling day. As no difference between sampling days was observed, data from the two sampling days were pooled. In tap water control, a significant interaction between injection and dose indicated that a different dose-response relationship existed depending on whether or not the trout were injected with A. salmonicida. Dunnett's post-test was used to compare effluent concentrations with tap water control. Shown are mean values with $95 \%$ confidence intervals (CI) $\left(n \geq 9,{ }^{*} P \leq 0.05,{ }^{* *} P \leq 0.01\right)$.

Trout exposed to effluent did not show statistically significant differences in the proportions of erythrocytes, total leucocytes, granulocytes, thrombocytes or total lymphoid cells in blood (Table 1). There was also no effect of A. salmonicida-injection on these blood parameters. However, there was a significant component of variability observed due to sampling day in both erythrocytes and leucocytes.

There was a clear difference in the nature of the response of lymphocyte numbers to sewage effluent depending on whether or not the trout had been $A$. salmonicida-injected (Fig. 1). Lymphocyte data for A. salmonicida- and PBS-injected trout was analysed independently due to this interaction of injection and sewage exposure. The PBS-injected trout showed a statistically significant reduction in the proportion of lymphocytes as compared to the control group, whereas no sewage-related differences were observed in the A. salmonicida-injected group. It appears as if lymphocyte numbers were already reduced in the A. salmonicida-injected control group. When the PBS group was assessed independently of the A. salmonicida group, there was also a significant decrease on day 2 of sampling (data not shown).

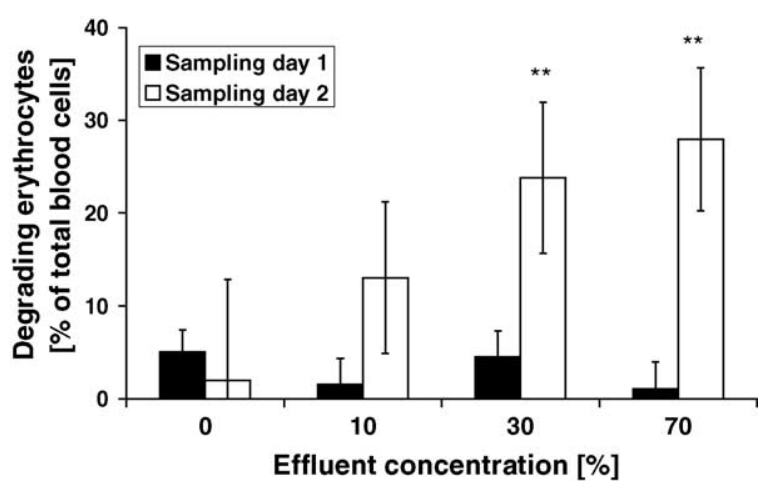

Fig. 2. Numbers of degrading erythrocytes in peripheral blood, given as percent of total blood cells counted. Data were tested using a threeway ANOVA with the variables effluent exposure, A. salmonicida/PBS-injection and sampling day. As no differences between $A$. salmonicida-injected and PBS-injected fish were observed, data from these two groups were pooled. Dunnett's post-test was used to compare effluent concentrations with tap water control. Shown are mean values with $95 \% \mathrm{CI}\left(n \geq 5,{ }^{* *} P \leq 0.01\right)$.

A high prevalence of degrading erythrocytes in peripheral blood was observed in fish sampled on the second sampling day. This putative stress effect increased with increasing effluent concentration (Fig. 2). Effluent-exposed trout displayed significantly enhanced erythrocyte degradation at 30 and $70 \%$ effluent in a concentration-dependent manner. In individuals sampled on sampling day 1, the manifestation of degrading erythrocytes in blood was not influenced by exposure to effluent.

Proliferation of Con A-stimulated lymphocytes was significantly enhanced after exposure to sewage effluent (Fig. 3a). The response was statistically significant at all three effluent concentrations. However, the magnitude of the response did not vary with the effluent concentration in a concentration-dependent manner. There was no apparent response in lymphocyte proliferation due to A. salmonicida-injection. Lymphocyte proliferation was also influenced by the sampling day, in that individuals from day 1 showed a higher level of proliferation than fish from day 2. Stimulation of peripheral blood leucocytes with LPS also resulted in enhanced proliferation after exposure to effluent. However, this was only statistically significant for the $70 \%$ effluent group (Fig. 3b). Sampling day did not have any significant effect on the proliferation of LPS-stimulated leucocytes. 

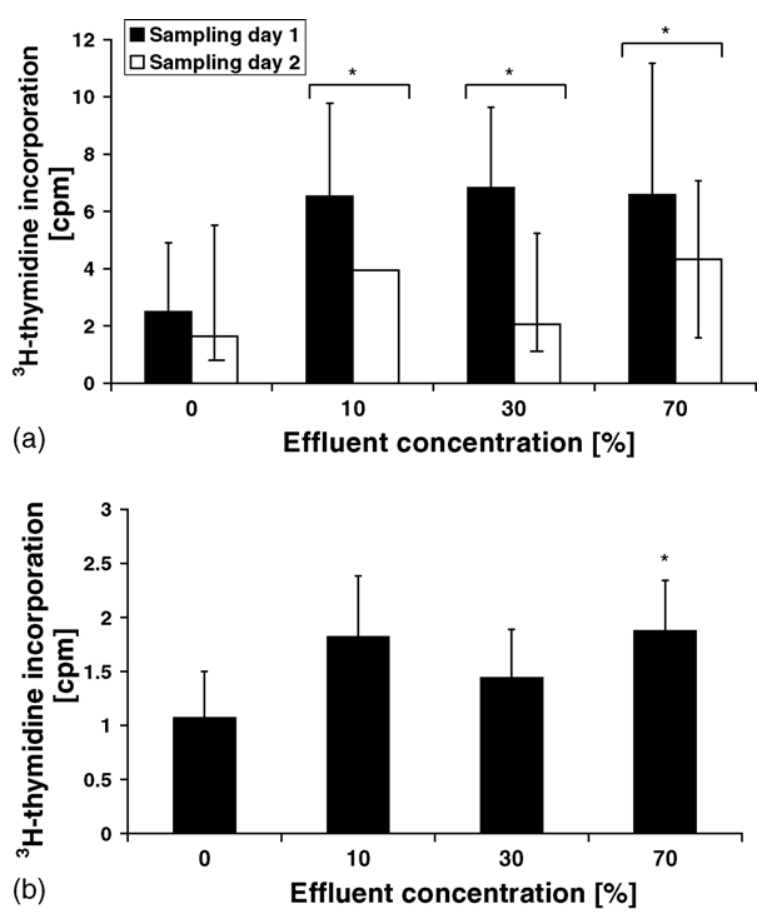

Fig. 3. Proliferation of (a) Con A-stimulated and (b) LPS-stimulated peripheral blood leucocytes given as ratio of ${ }^{3} \mathrm{H}$-thymidine incorporation (cpm) of mitogen-stimulated cells to unstimulated control cells. Data was tested using a three-way ANOVA with the variables effluent exposure, A. salmonicida-/PBS-injection and sampling day. Injection of trout with either A. salmonicida or PBS did not influence cell proliferation in either assay type (ConA- as well as LPSstimulation). Results from both groups were thus pooled for the respective mitogen treatment. For (a) a significant effect of sampling day was found ( $n \geq 3$, except for the group with $10 \%$ effluent, sampling day 2: $n=2$ ); for (b) no effect of sampling day was observed and data from both days were thus pooled $(n \geq 9)$. Shown are mean values with $95 \%$ CI. Dunnett's post-test was used to compare effluent concentrations with tap-water control $\left({ }^{*} P \leq 0.05\right)$.

Liver EROD activity increased after exposure to 10 and 30\% effluent, however, only EROD activity in trout exposed to $30 \%$ STP effluent was significantly higher compared to trout held in de-chlorinated tap water (Fig. 4). Exposure to 70\% effluent resulted in only slightly higher liver EROD activity compared to control fish indicating that an inhibitory effect may have occurred in response to the highest effluent concentration. Liver EROD activity was also not influenced by injection with inactivated A. salmonicida.

The concentration of PAH equivalents, namely naphthalene and pyrene compounds were significantly

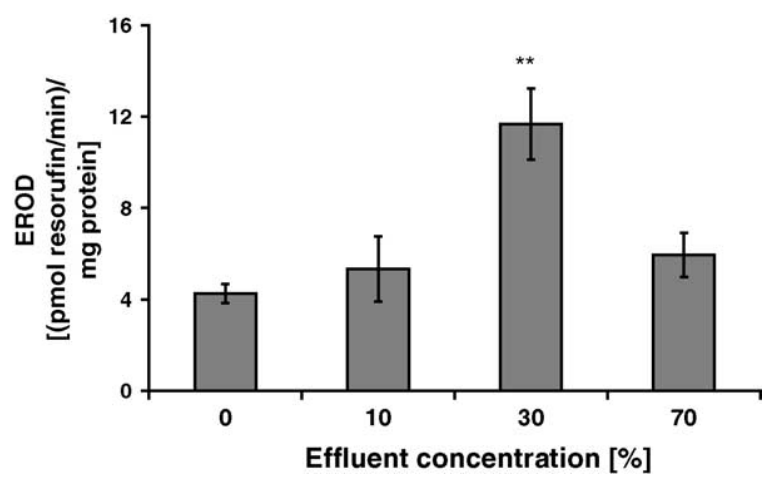

Fig. 4. Liver EROD activity, given as resorufin produced per min and mg protein. Data were tested using Kruskal-Wallis non-parametric one-way ANOVA. Shown are median values with standard error of the means $\left(n \geq 16,{ }^{* *} P \leq 0.01\right)$.

increased in bile samples of trout exposed to effluent (Fig. 5). Naphthalene equivalents increased in a dosedependent manner and were significantly elevated at all effluent concentrations. Pyrene equivalents were significantly elevated at 10 and $70 \%$ effluent, but not at $30 \%$. Benzo[a]pyrene equivalents did not show a clear response pattern, but were elevated in bile samples from fish exposed to $10 \%$ effluent. These data indicate that smaller molecular weight compounds such as pyrene and naphthalene seem to predominate in bile. There were no significant correlations between the logarithm of PAH equivalent concentrations and the logarithm of EROD as assessed with individual fish data. However, as there appeared to be EROD inhibition in the $70 \%$ effluent concentration, the correlations were reassessed with these data removed. This resulted in a

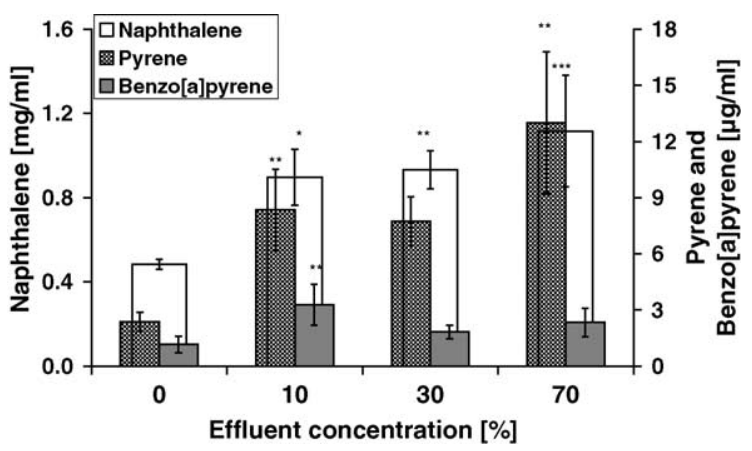

Fig. 5. PAH equivalents in bile samples. Data were tested using Kruskal-Wallis non-parametric one-way ANOVA. Shown are median values with standard error of the means $\left(n \geq 10,{ }^{*} P \leq 0.05\right.$, $\left.{ }^{* *} P \leq 0.01,{ }^{* * *} P \leq 0.001\right)$. 
statistically significant correlation between naphthalene equivalents and EROD activity $(r=0.4, P=0.15$, $n=38$ ), but no significant correlations were observed with EROD and pyrene or benzo[a]pyrene equivalents.

\section{Discussion}

In this study, exposure of trout to high concentrations of a well treated municipal sewage effluent resulted in no net mortality. The only immunological and haematological parameters that were altered by effluent exposure were circulating lymphocytes, in vitro lymphocyte proliferation and degradation of red blood cells. These parameters and their response to sewage effluent exposure interacted with short-term sampling stress, or to injection with an inactivated fish pathogen. Other non-specific immune functions such as lysozyme, oxidative burst and phagocytosis did not respond to either effluent exposure or to Aeromonasinjection. Trout demonstrated elevated levels of bile PAH metabolites and induced liver monooxygenase activity likely indicating exposure to PAHs.

The only peripheral blood leucocytes that appeared to be influenced by effluent exposure were lymphocytes. However, the observed decrease in lymphocyte numbers was only apparent in sham-injected, but not in A. salmonicida-exposed trout. The A. salmonicidaexposed trout from the control group appeared to have lymphocyte numbers that were similar to effluent exposed groups. Thus we would conclude that the $A$. salmonicida injection itself may have resulted in decreased lymphocyte numbers, precluding the detection of effluent effects in the A. salmonicida-injected treatments.

Effects of exposure to sewage treatment water on blood cell differentials in salmonid fish have been observed previously (Hitzfeld et al., 2000; Prietz et al., 2000). Brown trout (Salmo trutta f. fario) exposed to water samples from different sewage treatment steps displayed significantly lower leucocyte counts in peripheral blood compared to tap water controls. In line with our results, the decreased leucocyte numbers found in this study were mainly due to lower lymphocyte counts. Lower numbers of granulocytes and lymphocytes have also been observed in goldfish $(C$. auratus) exposed to 10 and $20 \%$ treated sewage in a laboratory scale experiment (Kakuta, 1997).
The decrease in lymphocyte numbers in shaminjected fish found in the present study was possibly caused by either a stress response or by anthropogenic compounds such as PAHs. Exposure of trout to PAHs has previously been shown to cause a reduction in peripheral blood lymphocyte counts (Karrow et al., 1999). In a field study, Khan (2003) also observed lower numbers of circulating lymphocytes in three flatfish species sampled at a PAH-contaminated site, compared to fish from a reference site. However, another possible explanation for the observed effects on blood lymphocyte numbers is the influence of handling stress. It has been demonstrated that the stress hormone cortisol selectively causes apoptosis of activated B-cells (Weyts et al., 1998). Decreases in lymphocytes due to sampling stress were also observed in our study. Therefore, a combination of B-cell activation due to effluent exposure or A. salmonicida-injection with elevated cortisol levels as a consequence of handling stress could have caused the decrease in lymphocyte numbers observed in the present study.

Proliferation of Con A- and LPS-stimulated lymphocytes was increased in virtually the opposite fashion as circulating lymphocytes were decreased. It is unlikely that such an increase could be attributed to stress as Con A-stimulated lymphocyte proliferation was decreased on day 2 of sampling compared to day 1 . Thus, this response is more likely related to the effects of toxicants within the effluent. This finding is in contrast with a study by Price et al. (1997), who found a significant reduction in the proliferative responses of T- and B-lymphocytes in carp $(C$. carpio) exposed to effluent-receiving river water in southeast UK.

Blood cell differentials also revealed that exposure to effluent increased the fragility of erythrocytes in a concentration-dependent manner. This result was not observed immediately as only trout sampled on the second day of sampling showed a marked increase in degrading erythrocytes. It is likely that the exposure to effluent has some impact on the integrity of erythrocyte membranes. It has moreover been established that adrenalin causes rapid erythrocyte swelling which in this case could have resulted in lysis of compromised cells explaining why the observation is only evident on day 2. These findings indicate that exposure of fish to a combination of stress factors could result in an amplification of adverse effects. Effects of wastewater effluent 
on erythrocytes in fish have been shown before. Male fathead minnows (Pimephales promelas) kept in a constructed wetland system showed decreased haematocrit values after exposure to high sewage effluent concentrations at the inflow site, when compared to control fish or to fish further downstream (Hemming et al., 2001). Kakuta (1997) also reported lower erythrocyte numbers in peripheral blood of goldfish, exposed to treated sewage in a laboratory experiment. Amphiphilic compounds such as resin acids have been observed to cause hemolysis of erythrocytes, presumably through intercalation into the lipid bilayer (Bushnell et al., 1985). Thus, amphiphilic compounds such as fatty acids, known to be elevated in sewage effluent may have caused erythrocyte lysis in this study.

Serum lysozyme activity, head kidney macrophage activity and serum level of $A$. salmonicida-specific antibodies were not influenced by acute exposure to sewage treatment effluent in the present study. In contrast to these results, Price et al. (1997) showed a decrease in serum lysozyme activity in effluent-exposed carp compared to fish from a control (high water quality) site. Kakuta (1997) moreover observed a decrease of phagocytotic activity in blood cells of goldfish exposed to treated sewage.

As well as enabling the assessment of specific antibody production as a measure of specific humoral immunity, injection of trout with A. salmonicida was chosen as a stimulant of the immune system. While in sham-injected fish, exposure to effluent decreased lymphocyte numbers, fish already affected by A. salmonicida (as can be seen in the control) did not experience further adverse effects on their lymphocyte numbers due to effluent exposure. If injection of fish with a pathogen and exposure to effluent are both regarded as stress factors affecting blood lymphocyte numbers, it could be assumed that the stress caused by the pathogen is already so pronounced that a further stress (in this case effluent exposure) does not cause a further decrease in lymphocyte numbers. The specific timing of the injection with A. salmonicida and sampling (28 days) was optimised to provide measurable levels of $A$. salmonicida-specific IgM. Production of $A$. salmonicida-specific antibodies in rainbow trout has been shown to only start after 18 days, depending on the number of bacteria injected, while considerable levels are observed as late as 30 days after challenge (Köllner et al., 2002). The observation that other immune pa- rameters did not respond to injections was likely an indication of timing, rather than the lack of response. In contrast to antibody production, non-specific immune parameters, such as oxidative burst are known to respond very rapidly to antigens. Thus, we would conclude that it is likely that non-specific endpoints responded to $A$. salmonicida-injection and subsequently returned to baseline levels prior to sampling.

Induction of liver EROD activity is widely used as an indicator for pollution and subsequent activation of detoxification mechanisms (cytochrome P450 1A1) in the vertebrate liver (Bucheli and Fent, 1995; Cousinou et al., 2000) and has been linked to exposure to PAHs and PCBs (Stegeman and Hahn, 1994; Rice and Schlenk, 1995). In the present study, EROD activity in trout liver was observed to increase after exposure to sewage treatment effluent, which could be caused by the presence of elevated PAH concentrations, as found in bile samples of effluent exposed fish. The correlation of naphthalene equivalent concentrations in bile samples with EROD activity in individual tout supports this conclusion. The lower level of EROD activity found in fish exposed to the highest effluent concentration in our study, is likely due to inhibition of $\mathrm{P} 450$ activity by higher concentrations of toxic substances in liver tissue. Such an inhibiting effect on EROD activity in fish has been demonstrated after application of high concentrations of PCBs in vitro and in vivo (Gooch et al., 1989; Monosson and Stegeman, 1991; Hahn et al., 1993) and exposure to the estrogenic compound nonylphenol (Arukwe et al., 1997), as well as in field studies with fish caught at contaminated sites (Elskus et al., 1989). McArdle et al. (2000), however, found that such an inhibitory effect on liver EROD activity cannot necessarily be expected after exposure to high sewage effluent concentrations (75\%), but seems to be strongly dependent on the compound mixture present in the investigated effluent.

In general, this study has revealed effects of sewage treatment effluent on selected immune parameters in rainbow trout. As well as the effluent effects, handling stress has been shown to play a pronounced role and should thus be considered as a possible confounding factor and analysed accordingly in all studies on immune performance in fish. Circulating lymphocytes, lymphocyte proliferation and erythrocyte integrity appeared to be particularly sensitive to both the effects of effluent exposure and the effects of stress. Like 
in all studies on immunotoxicological effects, alterations in the reactivity of selected immune parameters cannot be rated as indicative for the resulting overall immune competence without specific evidence of increased probability of infection. However, the discovery that immune reactivity in fish can be influenced by exposure to effluent, is suggestive of the potential for adverse influence on immune competence and subsequently a possible decrease in disease resistance.

\section{Acknowledgements}

The study was supported by a travel grant from the Universitätsgesellschaft e.V., University of Konstanz and by a scholarship to B. Hoeger from the German Federal Environmental Foundation, Osnabrück. Research in New Zealand was funded by the Foundation for Research Science and Technology. The authors would like to thank Rosanne Ellis, Megan Finley and Murray Smith (Forest Research, Rotorua, New Zealand) for practical help and Bernd Köllner, Günter Kotterba and Uwe Fischer (Friedrich-Löffler-Institut, Greifswald-Insel Riems, Germany) for providing $A$. salmonicida and trout IgM-specific antibodies as well as scientific support.

\section{References}

Aas, E., Baussant, T., Balk, L., Liewenborg, B., Andersen, O.K., 2000. PAH metabolites in bile, cytochrome P4501A and DNA adducts as environmental risk parameters for chronic oil exposure: a laboratory experiment with Atlantic cod. Aquat. Toxicol. 51, 241-258.

Arukwe, A., Förlin, L., Gosoyr, A., 1997. Xenobiotic and steroid biotransformation enzymes in atlantic salmon (Salmo salar) liver treated with an estrogenic compound, 4-nonylphenol. Environ. Toxicol. Chem. 16, 2576-2583.

Bucheli, T.D., Fent, K., 1995. Induction of cytochrom P450 as a biomarker for environmental contamination in aquatic ecosystems. Crit. Rev. Environ. Sci. Technol. 25, 201-268.

Bushnell, P.G., Nikinmaa, M., Oikari, A., 1985. Metabolic effects of dehydroabietic acid on rainbow trout erythrocytes. Comp. Biochem. Physiol. C 81, 391-394.

Cousinou, M., Nilsen, B., Lopez-Barea, J., Dorado, G., 2000. New methods to use fish cytochrome P4501A to assess marine organic pollutants. Sci. Total Environ. 247, 213-225.

Daughton, C.G., Ternes, T.A., 1999. Pharmaceuticals and personal care products in the environment: agents of subtle change? Environ. Health Perspect. 107, 907-938.
Ellis, A.E., 1990. Lysozyme assays. In: Van Muiswinkel, W.B. (Ed.), Techniques in Fish Immunology. SOS Publications, Fair Haven, pp. 101-103.

Elskus, A.A., Stegeman, J.J., Susani, L.C., Black, D., Pruell, R.J., Fluck, S.J., 1989. Polychlorinated biphenyls concentration and cytochrome P-450E expression in winter flounder from contaminated environments. Mar. Environ. Res. 28, 25-30.

Gooch, J.W., Elskus, A.A., Kloepper-Sams, P.J., Hahn, M.E., Stegeman, J.J., 1989. Effects of ortho- and non-ortho-substituted polychlorinated biphenyl congeners on the hepatic monooxygenase system in scup (Stenotomus chrysops). Toxicol. Appl. Pharmacol. 98, 422-433.

Guillette Jr., L.J., Guillette, E.A., 1996. Environmental contaminants and reproductive abnormalities in wildlife: implications for public health? Toxicol. Ind. Health 12, 537-550.

Hahn, M.E., Lamb, T.M., Schultz, M.E., Smolowitz, R.M., Stegemann, J.J., 1993. Cytochrome P450 1A induction and inhibition by $3,3^{\prime}, 4,4^{\prime}$-tetrachlorobiphenyl in an Ah receptor-containing fish hepatoma cell line (PLHC-1). Aquat. Toxicol. 26, 185-208.

Hemming, J.M., Waller, W.T., Chow, M.C., Denslow, N.D., Venables, B., 2001. Assessment of the estrogenicity and toxicity of a domestic wastewater effluent flowing through a constructed wetland system using biomarkers in male fathead minnows (Pimephales promelas Rafinesque, 1820). Environ. Toxicol. Chem. 20, 2268-2275.

Hitzfeld, B.C., Prietz, A., Dietrich, D.R., 2000. Gesundheitszustand der Fische im Rheintal, Expositionsversuche 1999: Untersuchungen zum Immunstatus. Department Environmental Protection, Canton St. Gallen, Switzerland, p. 87.

Jobling, S., Nolan, M., Tyler, C.R., Brighty, G.C., Sumpter, J.P., 1998. Widespread sexual disruption in wild fish. Environ. Sci. Technol. 32, 2498-2506.

Kakuta, I., 1997. Effect of sewage on blood parameters and the resistance against bacterial infection of goldfish, Carassius auratus. Environ. Toxicol. Water Qual. 12, 43-51.

Karrow, N.A., Boermans, H.J., Dixon, D.G., Hontella, A., Solomon, K.R., Whyte, J.J., Bols, N.C., 1999. Characterizing the immunotoxicity of creosote to rainbow trout (Oncorhynchus mykiss): a microcosm study. Aquat. Toxicol. 45, 223-239.

Khan, R.A., 2003. Health of flatfish from localities in Placentia Bay, Newfoundland, contaminated with petroleum and PCBs. Arch. Environ. Contam. Toxicol. 44, 485-492.

Köllner, B., Kotterba, G., 2002. Temperature dependent activation of leucocyte populations of rainbow trout, Oncorhynchus mykiss, after intraperitoneal immunisation with Aeromonas salmonicida. Fish Shellfish Immunol. 12, 35-48.

Köllner, B., Wasserrab, B., Kotterba, G., Fischer, U., 2002. Evaluation of immune functions of rainbow trout (Oncorhynchus mykiss) - how can environmental influences be detected? Toxicol. Lett. 131, 83-95.

Kummerer, K., 2001. Drugs in the environment: emission of drugs, diagnostic aids and disinfectants into wastewater by hospitals in relation to other sources-a review. Chemosphere 45, 957969.

Luebke, R.W., Hodson, P.V., Faisal, M., Ross, P.S., Grasman, K.A., Zelikoff, J., 1997. Aquatic pollution-induced immunotoxicity in wildlife species. Fundam. Appl. Toxicol. 37, 1-15. 
McArdle, M., Elskus, A., McElroy, A., Larsen, B., Benson, W., Schlenk, D., 2000. Estrogenic and CYP1A response of mummichogs and sunshine bass to sewage effluent. Mar. Environ. Res. 50, 175-179.

Monosson, E., Stegeman, J.J., 1991. Cytochrome P450E (P450IA) induction and inhibition in winter flounder by $3,3^{\prime}, 4,4^{\prime}$ tetrachlorobiphenyl comparison of response in fish from Georges Bank and Narragansett Bay, Rhode Island, USA. Environ. Toxicol. Chem. 10, 765-774.

Price, M.A., Jurd, R.D., Mason, C.F., 1997. A field investigation into the effect of sewage effluent and general water quality on selected immunological indicators in carp (Cyprinus carpio L.). Fish Shellfish Immunol. 7, 193-207.

Prietz, A., Fleischhauer, V., Hitzfeld, B., Dietrich, D.R., 2000. Effects of stream water on immune parameters of brown trout (Salmo trutta f. fario). In: Proceedings of the Third SETAC (Society of Environmental Toxicology Chemistry) World Conference, Poster Presentation, May 2000.

Rice, C.D., Schlenk, D., 1995. Immune function and cytochrome P4501A activity after acute exposure to $3,3^{\prime}, 4,4^{\prime}, 5$ pentachlorobiphenyl (PCB 126) in channel catfish. J. Aquat. Anim. Health 7, 195-204.

Rosenkranz, A.R., Schmaldienst, S., Stuhlmeier, K.M., Chen, W., Knapp, W., Zlabinger, G.J., 1992. A microplate as- say for the detection of oxidative products using $2^{\prime}, 7^{\prime}$ dichlorofluorescin-diacetate. J. Immunol. Meth. 156, 3945.

Secombes, C.J., 1990. Isolation of salmonid macrophages and analysis of their killing activity. In: Van Muiswinkel, W.B. (Ed.), Techniques in Fish Immunology. SOS Publications, Fair Haven, pp. 101-103.

Stegeman, J.J., Hahn, M.E., 1994. Biochemistry and molecular biology of monooxygenases: current perspectives on forms, functions, and regulation of cytochrome $\mathrm{P} 450$ in aquatic species. In: Ostrander, G.K., Malins, D. (Eds.), Aquat. Toxicol.: Mol., Biochem. Cell. Perspect. Lewis Publishers, Boca Raton, FL, p. 87.

van den Heuvel, M.R., Power, M., MacKinnon, M.D., Dixon, D.G., 1999. Effects of oil sands related aquatic reclamation on yellow perch (Percaflavescens). II. Chemical and biochemical indicators of exposure to oil sands related waters. Can. J. Fish. Aquat. Sci. $56,1226-1233$.

Weyts, F.A., Flik, G., Rombout, J.H., Verburg-van Kemenade, B.M., 1998. Cortisol induces apoptosis in activated B cells, not in other lymphoid cells of the common carp, Cyprinus carpio L. Dev. Comp. Immunol. 22, 551-562.

Wilkinson, L., 1990. SYSTAT: The System for Statistics. SYSTAT Inc., Evanston, IL, USA. 